\title{
Abordagem cívica e jesuítica da história do Brasil para crianças, no livro do Padre Raphael Maria Galanti ${ }^{1}$
}

Civic and Jesuitical approach to the history of Brazil for children, in the book of Father Raphael Maria Galanti

\author{
Ligia Bahia de Mendonça \\ PCRJ, PROPED, Universidade do Estado do Rio de Janeiro, Rio de Janeiro, Brasil, \\ ligiabahia@gmail.com
}

\section{Resumo}

Investigar a abordagem cívica e jesuítica do livro "Breve História do Brasil", publicado em 1913, voltado para crianças do curso primário pela trajetória docente e viagens pastorais de seu autor, o jesuíta italiano Padre Raphael Maria Galanti é o objetivo deste artigo. A obra didática, publicada na primeira década do século XX, narra "fatos" históricos e heroicos, desde os "fatos que levaram ao descobrimento do Brasil até a República", "fala ao coração", com objetivo de cativar a criança e prender sua atenção, com intuito da pedagogia moral, utilizando cronologia histórica rigorosa e um questionário ao final de cada capítulo, voltado, principalmente, para a memorização do ensinado, como prescrevia o "Ratio Studiorum", o método pedagógico dos jesuítas.

Palavras-chave: Livro didático de história. Raphael Maria Galanti. Intelectuais.

\begin{abstract}
Investigating the civic and Jesuitical approach of the book "Brief History of Brazil", published in 1913, aimed at primary school children through the teaching and pastoral journeys of its author, the Italian Jesuit Father Raphael Maria Galanti is the purpose of this article. The didactic work, published in the first decade of the twentieth century, narrates historical and heroic "facts", from "facts that led to the discovery of Brazil to the Republic", "speaks to the heart", to captivate the child and attention, with a view to moral pedagogy, using a rigorous historical chronology and a questionnaire at the end of each chapter, aimed mainly at the memorization of the taught, as prescribed by the Ratio Studiorum, the pedagogical method of the Jesuits.
\end{abstract}

Keywords: History textbook. Raphael Maria Galanti. Intellectuals. 


\section{O ensino de História para crianças}

Investigar a abordagem cívica e jesuítica do livro "Breve História do Brasil", publicado em 1913, voltado para crianças do curso primário pela trajetória docente e viagens pastorais de seu autor, o jesuíta italiano Padre Raphael Maria Galanti é o objetivo deste artigo. Na República recém-proclamada buscava-se moldar as crianças de acordo com o civismo e patriotismo, de acordo com um projeto cívicopedagógico do novo regime. Concepção, que levou muitos autores a se dedicarem a este tipo de suporte de escrita, pois revelaram a crença no papel transformador da educação como estratégia para civilizar a nação.

No campo dos intelectuais, dialogo com François Sirinelli (2003, p. 262) que sugere uma circulação "entre os três níveis - ideologia, cultura política e "mentalidades coletivas", propondo desta forma, os intelectuais como produtores de bens simbólicos, criadores e mediadores culturais e como atores políticos, relativamente engajados na vida da cidade e/ou nos locais de produção e divulgação de conhecimento e produção de debates (Sirinelli, 2003; Gontijo, 2005). Afirma o autor que a sociabilidade que pode ser fomentada através das experiências, espaços e tempos vividos por estes sujeitos, pode nos revelar sobre as atividades e comportamentos destes intelectuais (Sirinelli, 2003), situando assim, os institutos a que foram afiliados.

Apreender sobre a relevância das experiências e trajetórias vividas pelos professores primários, por meio das suas experiências pessoais, das suas leituras e das suas influências socioculturais, para o projeto político e educativo da época Schueler (2009) - que os estuda no Império brasileiro - torna-se necessário para reconstituir o itinerário percorrido por padre Galanti. Para a historiadora foi com a escolarização o que livro didático se configurou um suporte importante na formação de alunos e professores, atraindo muitos intelectuais à sua escrita.

A História do livro, relevante e crescente, no campo da História da Educação, principalmente pela influência de autores identificados com movimento da História Cultural e Nova História Cultural, que usaram os livros como fontes e objetos de estudos.

$\mathrm{Na}$ literatura francesa, por meio de Roger Chartier (1990), possibilitou nova abordagem sobre a leitura e os leitores na Europa. O livro passa a ser objeto de estudo na Europa fazendo do livro, "um objeto comum e uma narrativa singular, ligando a particularidade de uma história e a banalidade de uma forma, pondo como questão central os efeitos desejados ou produzidos através da apresentação impressa de tal narrativa" (Chartier, 1990, p. 86). Desta forma, interessava as práticas de leituras, pois era possível a partir daí sua representação de mundo, notar o currículo e conhecimento em voga na sociedade.

Robert Darnton (1990) refletiu sobre o papel dos meios de comunicação, da leitura e do lluminismo, dedicando-se aos leitores comuns, sobre o que liam, como liam e qual o significado desta leitura na vida destes sujeitos, onde autor e leitor assumiam uma posição ideal de leitura do texto.

Na Itália, Carlo Ginzburg (1987), ao encontrar, por acaso, um processo do século $\mathrm{XVI}$, do moleiro Menocchio, analisa a vida deste camponês pautado na leitura e na oralidade da cultura popular. Natalie Zemon Davis (1990) também analisa no século XVI a experiência de indivíduos comuns a partir da difusão da palavra impressa. Todos esses autores puderam ser úteis para entender o papel do livro.

Os estudos sobre o livro didático no Brasil se ampliaram e tem se mostrado relevante, pelo necessário percurso de todo movimento editorial, para além da 
análise dos livros e seu conteúdo (Frade \& Maciel, 2006). Ponto relevante também são os que se dedicaram às descrições físicas, validação e difusão (Fernandes \& Felgueiras, 2000).

$\mathrm{Na}$ década de 90, Circe Bittencourt defendeu sua tese sobre os livros didáticos, pesquisa que impulsiona tantos outros trabalhos no Brasil, tratando além de questões das políticas educacionais, rumou para múltiplas dimensões como o editorial do livro para o mercado, instrumento de saber e ensino, como suporte nas disciplinas escolares e os usos e as práticas que recaem sobre este material ${ }^{2}$.

Arlete Gasparello (2002) analisando o ensino secundário brasileiro no Colégio Pedro II e o programa de ensino de história nacional traçou identidade dos livros didáticos de História ${ }^{3}$.

Entre muitos outros estudos, três pesquisas se aproximam de forma particular ao meu tema neste artigo: Hansen (2007) aponta que intelectuais importantes se dedicaram a literatura cívico-pedagógica infantil, ligando-a a um ideal de infância brasileira; Teixeira (2008) concebe os livros como veículo de saber, mas também de controle do povo. Indica também, que livros de história foram utilizados como livro de leitura ${ }^{4}$; Silva $(2008,2012)$ aponta as relações entre ensino de história e o mercado editorial de livros didáticos de História do Brasil ${ }^{5}$.

\section{Padre Galanti: autor de manuais escolares}

Nascido na pequena cidade italiana de Ascoli-Piceno, em 15 de novembro de 1840, o Intelectual ingressou Companhia de Jesus em 1860, na qual desempenhou diversas funções até 1917, quando faleceu. Nos estudos, além do estudo obrigatório que duraram 14 anos, se dedicou ainda Literatura e Filosofia; nas viagens, esteve em estados e capitais brasileiras como: Florianópolis, São Paulo, Pará e Rio de Janeiro, nos quais se dedicou ao magistério; e em países como: Roma, Inglaterra e Bélgica, como parte de sua formação na Ordem. Atuou como professor em vários Colégios e Seminários jesuíticos brasileiros, e ainda como, historiador escreveu diversas obras didáticas, o que o legitimou acadêmica e socialmente ${ }^{6}$.

Seu percurso profissional até a chegada ao Colégio Anchieta ainda é de difícil reconstituição, embora seja relevante para entender o autor e sua obra, pois como lembra Sirinelli (1996)

[...] as trajetórias pedem naturalmente esclarecimento e balizamento, mas também e, sobretudo interpretação. O estudo dos itinerários só pode ser um instrumento de investigação histórica se pagar esse preço. Sob a condição, entretanto, de evitar as generalizações apressadas e as aproximações duvidosas. A nós nos parece que a extrema diversidade das situações individuais impede que se chegue a explicações globalizantes. (Sirinelli, 1996, p. 247).

Apesar da dificuldade na reconstituição de sua trajetória, por meio de pistas deixadas pelo e sobre o padre, identifiquei a circulação do religioso por vários colégios jesuítas brasileiros, dentre os quais o do Santíssimo Salvador de Desterro, em Florianópolis no ano de1866, onde lecionou: Grego, Latim, Geografia e História Universal. Esteve também no Colégio São Luiz de Itu, em São Paulo, entre os anos de 1874 e 1876, onde ensinou Filosofia e História Eclesiástica; Antes de lecionar Filosofia e História Eclesiástica no Seminário em Belém (1878 - 1880), a pedido do 
bispo D. Antônio de Macedo Costa ${ }^{7}$, Galanti o acompanhou em "visitas pastorais", subindo o rio Madeira até o rio Santo Antônio, onde evangelizou moradores locais e um grupo de americanos que trabalhavam na construção da ferrovia Mamoré; novamente, em 1881, no Colégio na cidade de Itu ensinou Gramática inglesa, História universal e História do Brasil e de nesta instituição escreveu a maioria de suas obras. Por fim, em 1898, foi para o Colégio Anchieta de Nova Friburgo, no Rio de Janeiro, onde lecionou História até ficar doente e falecer, no início do século XX.

Sobre as suas i viagens, sejam "pastorais" (como as define o padre Galanti) e as outras que fez pelo país, percebi que, mesmo sem ter, ainda seus livros editados, desejou ser conhecido, e reconhecido como intelectual, por seus pares e possíveis leitores, legitimando-se ${ }^{8}$. Pois, mesmo, sem ter seus livros editados e disponibilizados era uma forma de se tornar um intelectual conhecido para seus pares e para possíveis leitores, e assim fazer circular sua escrita.

O padre italiano, durante suas viagens deparou-se com políticas educacionais e práticas pedagógicas (Mignot \& Gondra, 2007) diversas, dentro e no exterior do Brasil. Ao chegar ao Colégio Anchieta, na região serrana do rio de janeiro, não faz mais viagens, mas deixa, ainda, impregnado na sua escritura, suas impressões e conhecimentos adquiridos que se revelam nas inúmeras práticas que vivenciou e pretendeu socializar nos manuais que escreveu.

\section{O livro: Breve História do Brasil}

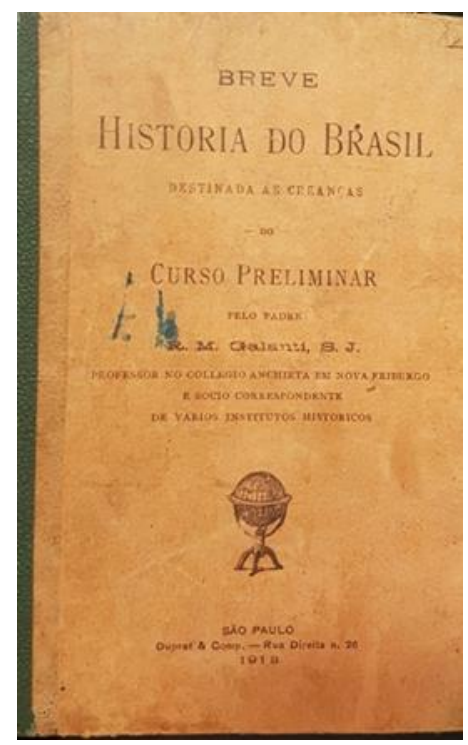

Figura 1 - Capa Breve História do Brasil destinado às crianças do Curso Preliminar,1913

O jesuíta atuou na educação brasileira por meio dos colégios da Companhia de Jesus, voltados para elite masculina da época, lecionou nas disciplinas de História Universal e do Brasil, principalmente. Galanti transformou sua experiência em manuais didáticos, Circe Bittencourt (2004) afirma que a organização das lições por parte dos professores tornou-se comum a partir do século XIX, à medida que crescia o número de escolas públicas e privadas, e ao mesmo tempo a convite das editoras. Explicando, que talvez não tivesse escrito os livros tardiamente, mas que apenas a partir daquele período passou-se a ser comum, professor também se tornar autor. 
O padre que há muito se dedicava às aulas de história, se consagrou na escrita de livros para o Ensino Secundário desde o final do século XIX, principalmente os de História Universal e do Brasil, mas somente em 1913 escreveu um livro destinado às crianças: Breve História do Brasil destinada as creanças do Curso Preliminar, editado pela Duprat \& Comp.

$\mathrm{Na}$ imagem da capa atento para a materialidade do impresso chamo atenção para o que explicita Munakata (2012, p. 185) "apreender a materialidade é, antes, conhecer o processo de produção, circulação e consumo de livros, no interior do qual seus elementos, por exemplo, o tamanho da página, adquire inteligibilidade." Busquei indícios na capa acima que me permitissem entender como se comunicava com o leitor, que empresa editara a obra e quando e outras pistas sobre o autor. Sua editora chamava-se Duprat, segundo Martins (2001) em sua obra pioneira sobre revistas e o papel social que desempenharam no final do século XIX e Início do XX, ao tratar das editoras afirmou que,

A Duprat fundada por H. Knosel, em 1862 e adquirida por Jorge Secker, em 1890, com a euforia do Encilhamento transformou-se em Companhia Industrial de São Paulo, propriedade de comerciantes abastados, com Duprat como gerente. Em 1902 a Duprat \& Comp., tem como sócios o Barão Raimundo Duprat, futuro prefeito de São Paulo [1911 - 1914] e seu irmão Alfredo Duprat... (Martins, 2001, p. 177)

As mais antigas e as melhores aparelhadas editoras eram Duprat e Casa Vanorden. No entanto, ao lado de outras tipografias foi considerada de pequeno porte (Razzini, 2002, p.7). Foi responsável ainda pela impressão de dois periódicos: O Criador Paulista e a Farpa (1910). Com a nacionalização do ensino, por ocasião da República, nacionalizou-se também o livro escolar, observa-se nesta editoras em tantas outras, um número relevante de produções de manuais escolares.

Ainda na capa do manual escrito pelo padre é possível notar uma forma de diálogo com o leitor, quando se nomeia membro de muitos institutos sobre essas "referências" que o legitimava há destaques sobre origem, experiência no magistério e filiações acadêmicas. Silva (2008) afirmou grande destaque nas capas e contracapas sobre sua origem, experiência no magistério ou nos institutos de pesquisa que atuavam. Era a forma de apresentação de sua trajetória.

Revendo a capa do impresso, percebo o vocábulo "breve" na parte de cima, seguida do título História do Brasil (em negrito) seguido pela expressão destinada às crianças, talvez quisesse o editor deixar claro ao seu público leitor. Ainda refletir sobre a adjetivação de "breve" indago-me se significaria uma história incompleta ou apenas uma pequena iniciação à história pátria? A intenção do autor e do editor não pude confirmar, mas aponto que se comparado aos outros livros do padre, este pequeno livro é bem resumido.

A informação centralizada "curso preliminar", também em negrito, marca o uso nas escolas, no momento em que o processo de escolarização estava posto, com a difusão na "crença no poder da escola como fator de progresso, modernização e mudança social" (Souza, 2000, p. 11). O ensino de História na educação primária "tornava-se um meio útil para o desenvolvimento de sentimentos e faculdades nascentes nas crianças. Significava dizer que o mais importante era dispor o espírito das crianças para a ciência" (Souza, 2000, p. 22).

O nome do autor centralizado, em diferenciada e em negrito, legitimado pelo seu currículo e seu título demonstra a necessidade do uso pelas escolas mantidas 
pela Igreja Católica. Para Foucault (1992), o autor, ao dar seu nome próprio a uma obra, tem sobre a mesma responsabilidade, portanto, sujeito às sanções, neste caso, o Imprimatur, "nessa perspectiva, a função-autor que necessariamente estabelece vínculos diversos com a obra e cria identidades" (Foucault, 1992, p. 478).

Breve História do Brasil, com pouco mais de 100 páginas aborda, com uma Introdução bem sintética sobre os fatos que levaram ao descobrimento do Brasil. A partir daí divide-se em épocas, a primeira se intitula "O Brasil até o domínio da Espanha" (1500 - 1580), a segunda, "O Brasil sob o domínio da Espanha" (1581 1641), na terceira "Desde a restauração de Portugal até a chegada da família real ao Brasil" (1640 - 1808), "O Brasil centro da monarquia portuguesa" (1808 - 1822) é o título da quarta época, Reinado de D. Pedro I (1822 - 1831) é o título da quinta época, Reinado de D. Pedro II e Fim da monarquia, respectivamente até a República, quando Nilo Peçanha assume a presidência do país. Ao final de cada parte, o livro apresenta uma cronologia, ou datas principais, dos fatos relevantes do período anteriormente estudado, seguido por um questionário de 83 perguntas que se subdividem pelo período. Percebo o uso da memorização ou técnica mnemônica de aprendizagem que visava que o aluno retivesse as informações que leu e teria "aprendido". Os jesuítas, como os educadores do período, usavam essa técnica no sentido não só de reter o aprendido, mas, também, de tornar a avaliação dos questionários como avaliação de aprendizagem.

A Ratio Studiorum, promulgada em 1599, se beneficiou de mais de 50 anos de experiências dos colégios jesuítas, um texto diretivo, com funções dos dirigentes, professores e alunos, que segundo Klein (1997) recobre todos os seus aspectos, no que diz respeito a:

[...] grade curricular; enfoque das disciplinas; horário e calendário; programação; textos de estudo; metodologia de ensino e aprendizagem; avaliação, promoção e premiação dos alunos; funcionamento das academias, das congregações marianas e das atividades extra-classe; disciplina de professores e alunos e as relações entre si (Klein, 1997, p. 3).

O conjunto de regras foi utilizada nos colégios da Companhia até a sua supressão, em 1759. Com a restauração da Ordem, em 1814 passou por modificações e outros experimentos, assim como a inclusão das necessidades atuais no tocante a cada localidade, o desejo de um documento universal ficou distante, mas não foi abandonado. Ainda que tenha passado por algumas reformulações, como a de 1832, que nunca chegou a se ser promulgada por nenhum padre Superior.

O documento apresenta os momentos didáticos, dos quais destaco: "1) preleção do professor; 2) estudo particular do aluno, com trabalhos escritos e de pesquisa; 3) exercícios de memória; 4) repetições" (Klein, 19971, p. 3). Suponho que foi a partir desta didática que Galanti escreve seu livro e constrói sua metodologia. Se compararmos as suas obras ${ }^{9}$, os conteúdos são resumidos, na sua visão com nomes dos principais personagens e acontecimentos ocorridos naquele período.

A guisa de ilustrar esta metodologia seleciono a parte "Época IV - Reinado de Pedro II", um trecho do livro que versa sobre a Guerra do Paraguai:

O facto mais importante do reinado de Pedro II foi a guerra do Paraguay que durou cinco longo annos e custou ao Brasil para mais 
de cem mil vidas de seu filhos. A causa ou pretexto della foi a invasão exército imperial no Estado do Uruguai; pois, como o governo de Montividéo vexasse muito seriamente os brasileiros residentes naquellepaiz, o governo do Brasil entendeu que devia recorrer às armas para conseguir que lhe fizesse justiça... Os heróes principaes foram Caxias, Barroso, Osório, o conde d'Eu, Tamandaré, Inhaúma, Porto Alegre, o visconde de Pelotas, o barão de Itaqui, Polydoro Quintanilha Jordão, Argollo, Deodoro da Fonseca, Floriano Peixoto e muitos outros ${ }^{10}$ (Galanti, 1913, pp. $79-82$ ).

Padre Galanti narra as glórias do imperialismo brasileiro com um tom memorialístico, buscando enfatizar o ato heroico, que torna a pessoa um ser digno e perfeito. Ressalta com nomes os heróis desta façanha, suponho assim quanto era relevante para sua escrita a biografia destes modelos de homens perfeitos, virtude que deveriam ser seguidas pelas crianças.

Sobre este assunto o padre formula 40 perguntas, como estas a seguir:

60) Que regência nomearam no dia 7 de abril? Quando foi nomeada a permanente trina e quem a formou?

-Houve revoluções neste tempo? Quem as promoveu?

- Que aconteceu a José Bonifacio?

$[\ldots]$

- Que houve de particular em 1867?

- Que fizeram os aliados em 1868?

- Porque se retirou Caxias? Quem Ihe sucedeu?

- Que fez o Conde d'Eu? (galanti, 1913, pp. 83-86)

As perguntas são detalhadas, com destaque para as datas, as personagens e os acontecimentos, que remetem ao exercício de memorização e oralidade, ou seja, repetição que foi utilizado de forma recorrente, principalmente, nas escolas religiosas.

O autor não fez uso de referências aos seus pares, nem mesmo aos institutos, como consta em outras obras do autor a consulta a estas fontes. Possivelmente, com intenção de resumir o texto e torná-lo mais objetivo, a história pátria a partir do que conhecia ou do que se havia escrito até então.

Nesta obra não há a chancela "Imprimatur", com assinatura ali aposta da autoridade eclesiástica e data, como encontrei em vários outros livros do padre. Como aquela ordem, a que se refere Chartier (1994) instaurada pelos livros: "fosse a ordem de sua decifração, a ordem no interior do qual ele deve ser compreendido ou, ainda, a ordem desejada pela autoridade que o encomendou ou permitiu sua publicação" (Chartier, 1994, p.8).

Sobre os possíveis leitores ou leitura feita deste livro, obtive poucas informações, além de tal obra era livro usado nas escolas jesuíticas. Como lembrou Chartier (1994):

[...] a leitura - que raramente deixa marcas, e que, ao dispersar-se em uma infinidade de atos singulares, liberta-se de todos os entraves que visam submetê-las. Um tal projeto repousa, por princípio, num duplo postulado: que a leitura não está, ainda, inscrita no texto, e que há, por tanto distância pensável entre o sentido que lhe é imposto (por seu autor, pelo uso, pela crítica, etc.) e a interpretação que pode ser feitas por seus leitores; consequentemente, um texto só existe se 
houver um leitor para Ihe dar um significado (Chartier, 1994, p.8, p. 11).

Desta forma, pela notícia veiculada no Aurora Collegial, pude conhecer recepção ao livro então registrada naquele jornalzinho na sessão "Na estante":

Profundamente gratos pela captivante gentileza, os ex-sextanistas, pelas columnas desta Chronica, agradecem a S. Rev. A preciosa oferta, e, ao enviar ao querido professor um sincero "muito obrigado", hypothecam-Ihe seu reconhecimento ${ }^{11}(1913$, p. 3)

Os livros escolares, como os de Galanti, testemunharam o currículo oficial vigente e foram reveladores dos valores cívicos e morais predominantes num certo período, Lajolo e Zilberman (1999) refletem sobre a história esquecida e minimizada dos livros didáticos:

Apesar de ilustre, o livro didático é o primo pobre da literatura, texto para ler e botar fora, descartável porque anacrônico: ou ele fica superado dados os progressos da ciência a que se refere ou o estudante o abandona, por avançar em sua educação (Lajolo \& Zilberman, 1999, p. 120)

A descartabilidade e a necessidade de atualização, argumentos enfatizados pelas autoras, de certo prejudicam ao pesquisador o acesso às fontes, dificultam 0 estabelecimento da circulação e apagam pistas sobre saberes e valores difundidos.

Desta forma, entre diversos autores, apropriei-me de algumas pesquisas já realizadas para entender o livro de Galanti dedicado às crianças. Hansen (2007) utilizou A História do Brasil ensinada pela biografia dos seus heróis de Sílvio Romero (1890), Festas nacionais de Rodrigo Otávio (1893), América de Coelho Netto (1897), A terra fluminense de Olavo Bilac e Henrique Coelho Netto (1898), Porque me ufano do meu país de Afonso Celso (1901), Nossa Pátria de Virgílio Cardo de Oliveira (1903), Contos Pátrios de Olavo Bilac e Coelho Netto (1909), Poesias infantis de Olavo Bilac (1904), História de nossa terra de Júlia Lopes de Almeida (1907), Através do Brasil de Olavo Bilac e Manoel Bomfim (1910), O livro do escoteiro de Arnaldo Guinle e Mário Pollo (1915), Minha terra de Afrânio Peixoto (1916), Nossa pátria de Rocha Pombo (1917), também estudado por Alexandra L. Silva, Saudade de Tales Andrade (1919), Brasil! Diurnal Cívico de Joaquim Luis Osório (1920), Breviário Cívico de Coelho Netto (1921) e Catecismo Cívico de Augusto Mário Caldeira Brant (1921).

Hansen (2007) destaca que os textos cívicos pretenderam ocupar-se de uma pedagogia moral, segundo a autora:

[...] assumiram, além de sua finalidade principal e de forma complementar a ela, a função de inculcar nas crianças novas regras de civilidade, procurando impor um padrão de hábitos e comportamentos aos quais os indivíduos deveriam se condicionar, e que sintetizavam um ideal de homem, representado em potencial na infância brasileira (Hansen, 2007, p. 3). 
Em Nossa Pátria de Rocha Pomb, Silva (2012) aponta que era para aqueles que necessitavam "amar a pátria" e assim conheceriam "nossa história", mas, segundo a autora a leitura estava direcionada, ainda, para as camadas mais populares da sociedade, conforme destaca o autor: "Este livrinho é feito para a inteligência das crianças e dos homens simples do povo" (Pombo Apud Silva, 2012, p. 154). A autora elegeu alguns livros ${ }^{12}$, que tomo, como o faço, por base para entender os livros para crianças: A História do Brasil ensinada pela biografia de seus heróis de Sylvio Romero (1890) Lições de História do Brasil para uso das classes primárias, Joaquim Manuel de Macedo (1877) e Através do Brasil, de Manuel Bonfim e Olavo Bilac (1910). São estes, também, livros dedicados às crianças, o primeiro a partir do da biografia e da gravura como "metodologias" para o ensino das classes primárias reforçava o grande exemplo de personagens heroicos, valores ideais para formar o cidadão; o livro de Macedo, um livro com 528 páginas, composto além do conteúdo por questionários, recursos pedagógico que objetivava facilitar a memorização; no último livro, os autores, através da viagem de dois irmãos, buscava desenvolver nas crianças o gosto pela leitura e estimulava o conhecimento das gentes e paisagens do Brasil.

Esses livros e seus posteriores estudados por historiadores, mostram as metodologias para incentivar o cidadão que se pretendia formar enlevado pelo amor à pátria que se construía.

Quanto à linguagem usada pelo autor, comenta o articulista do jornal Aurora Collegial "em linguagem singela de modo que as creancinhas a quem se destina o livros possam desde logo reter em sua infantil e travessa memória os sábios ensinamentos do mestre ${ }^{13 "}$ (Idem).

No limiar do novo regime republicano é necessário compreender também o novo ideal e representação de criança, pelo menos para literatura cívica, "as crianças idealizadas como público alvo desta produção literária não deveriam se envergonhar da infância, pois esta é a fase em que precisavam estudar e se prepara para o futuro" (Hansen, 2007, p. 25).

Não obstantes a contribuição dos historiadores, busco refletir sobre o livro de Galanti não incluso nos estudos a que tive acesso, face à peculiaridade do autor ser um padre jesuíta e seu livro didático ser utilizado pelas escolas da Ordem.

No final do século XIX e início do XX, com a primeira Constituição republicana posta e no seu bojo a concretização da separação entre Igreja e Estado, a modernização da sociedade brasileira, reformas educacionais e pedagógicas no ensino primário tornaram possíveis a reorganização das escolas primárias.

Hansen (2007) chama atenção para a descrição, ou narrativa das obras cívicas que fornecem ao pesquisador pistas para entender a metodologia do ensino do civismo e patriotismo para as crianças. São essas "pistas" que me ajudam a compreender que a narrativa devia chegar ao coração infantil através da história dos heróis, de virtudes e dos bons sentimentos a serem desenvolvidos desde a tenra infância. As descrições, feitas por Galanti, também com conhecimentos necessários a desenvolver a brasilidade, tinham o mesmo objetivo. $O$ fato do livro de Galanti não se dedicar aos "homens simples", público a que destinara Rocha Pombo sua obra, permite inferir a necessidade, que talvez tenha sido atendida pelo padre, de formarse a criança da elite como patriota.

Mas, isso não significa uma linguagem diferenciada, como Silva (2012) apontou no livro de Rocha Pombo, que dedicou além das crianças aos "homens simples", talvez a explicação seja a inclinação de Galanti a formação da elite até pela razão de 
se considerar a criança "“homem pequeno" ou homens incompletos" (Hansen, 2007, p.11), com o objetivo de fazer da criança, um adulto patriota.

\section{Conclusões}

A despeito da grande circulação dos livros de ensino de história para o ensino secundário, o livro didático voltado para outros públicos, principalmente, as crianças foram de suma importância para a disseminação dos ideais republicanos. O livro de Galanti que trouxe uma narração sintética da História local e pátria, capaz de desenvolver valores morais e cívicos.

Como manuais escolares oferecem pistas de sua produção e circulação, também o livro de Galanti permitiu que pudesse estabelecer as suas vivências e aprendizados nas viagens, suas tentativas de legitimação e sua representação nas escolas jesuíticas desses impressos. No caso específico de padre Galanti, nota-se seu itinerário, intrinsecamente ligado à Companhia de Jesus, da qual fez parte, inclusive no que diz respeito às suas viagens e experiência no magistério.

\section{Referências}

Bittencourt, C. (2004). Autores e editores de compêndios e livros de leitura (18101910). Educação e Pesquisa, 30(3), 475-491.

Chartier, R. (1988). A História Cultural entre práticas e representações. Lisboa, Difel. Chartier, R. (1994). A ordem dos livros: leitores, escritores e bibliotecas na Europa entre os séculos XIV e XVIII (M. D. Priori, Trad.) Brasília. Brasília: EdUNB.

Chartier, R. (2005). Da história da cultura impressa à história cultural do impresso. Entrevista. Revista Brasileira de Ciências da Comunicação.

Certeau, M. de. (2007). A escrita da história. Tradução de Maria de Lourdes Menezes (2ª ed., 3ª reimp.). Rio de Janeiro: Forense-Universitária.

Darnton, R. (1990). O beijo de Lamourette: mídia, cultura e revolução. São Paulo: Cia das Letras.

Davis, N. Z. (1990). Culturas do Povo. Rio de Janeiro: Paz e Terra.

Frade, I. C. A. S., \& Maciel, F. I. P. (Org.) (2006). História da Alfabetização: produção, difusão e circulação de livros (MG/RS/MT - Séc. XIX e XX). Belo Horizonte: UFMG/FaE.

Fernandes, R., \& Felgueiras, M. (Org.). (2000). A escola primária: entre a imagem e a memória. Porto: Projeto Museu Vivo da Escola Primária.

Foucault, M. (1992). O que é o autor? [Lisboa]: Ed. Passagens, 1992.

Galanti, R. M. S.J. (1913). Breve História do Brasil destinado às Creanças do Curso Preliminar. Duptat \& Comp.

Galvão, A. M. O. (2002). Oralidade, memória e a mediação do outro: práticas de letramento entre sujeitos com baixos níveis de escolarização - o caso do cordel (1930-1950). Educ. Soc., (23)81, 115-142.

Gasparello, A. (2002). Construtores de identidades: os compêndios de História do Brasil do Colégio Pedro II (1838-1920). (Tese de Doutorado em Educação), Pontifícia Universidade Católica de São Paulo, São Paulo, Brasil. 
Ginzburg, C. (1987). O queijo e os vermes. O cotidiano e as idéias de um moleiro perseguido pela Inquisição. Cia das Letras, São Paulo.

Gontijo, R. (2005). História, cultura, política e sociabilidade intelectual. In R. Soihet, M. F. B. Bicalho, \& M. F. S. Gouvêa. Culturas Políticas: ensaios de história cultural, história política e ensino de história. Rio de Janeiro: Mauad.

Hansen, P. (2007). Brasil, um país novo: literatura cívico-pedagógica e a construção de um ideal de infância brasileira na Primeira República. São Paulo, Tese (Doutorado em História Social), Universidade de São Paulo, São Paulo, Brasil.

Hernadez Diaz, J. M. (2002). Etnografia e historia material de la escuela. In A. E. Benito, \& J. M. H. Diaz (Coords.). La memória y el deseo cultura de la escuela y educación deseada educación deseada (1를. ed.). Valencia: Tirant lo blanch.

Jornal Aurora Collegial(1905 - 1922). (1913). Colégio Anchieta. Nova Friburgo.

Klein, Luiz Fernando. (1997). Por uma abordagem história da pedagogia inaciana. Palestra no Seminário Internacional "Visão Inaciana da Educação". São Leopoldo (RS) UNISINOS. (Mimeo.)

Lajolo, M. \& Zilberman, R. (1999). Literatura Infantil Brasileira. São Paulo: Ática, 1999.

Martins, A. L. (2001). Revistas em revista - imprensa e práticas culturais em tempos de República, São Paulo (1890-1922). São Paulo: Edusp / Fapesp / Imprensa Oficial do Estado.

Mendonça, L. B. (2010). O silêncio da ação: Jesuítas no Brasil pós-Reforma Pombalina. UERJ - Rio de Janeiro.

Mignot, A. C. V., \& Gondra, J. G. (2007). Viagens de educadores e circulação de modelos pedagógicos. In A. C. V. Mignot, \& J. G. Gondra (Orgs.). Viagens pedagógicas. São Paulo: Cortez.

Munakata, K. (2014). O livro didático como mercadoria. Pro-Posições, (23)3, 51-66. Recuperado de http://www.scielo.br/scielo.php?script=sci_arttext\&pid=S010373072012000300004\&l a ng=pt.

Razzini, M. P. G. (2002). Práticas de leitura e memória escolar. In Congresso Brasileiro de História de Educação, Brasil, 2. Recuperado de. http://sbhe.org.br/novo/congressos/cbhe2/pdfs/Tema3/0303.pdf

Schueler, A. (2005). Combates pelo ofício em uma escola moralizada e cívica: a experiência do professor Manoel José Pereira Frazão. Revista brasileira de história da educação, 9, pp. 109-139.

Silva, A. L. (2008). Ensino e mercado editorial de livros didáticos de História do Brasil - Rio de Janeiro (1870-1924). (Dissertação de Mestrado em História), Instituto de Ciências Humanas e Filosofia, Rio de Janeiro, Brasil.

Silva, A. L. (2012). Escritas de viagem, escritas da história: estratégias de legitimação de Rocha Pombo no campo intelectual. (Tese de doutorado em Educação), Universidade Estadual do Rio de Janeiro, Rio de Janeiro, Brasil. Rio de Janeiro.

Sirinelli, F. (2003). Os Intelectuais. In R. REMOND. Por uma História Política ( $2^{\mathrm{a}}$ ed., Dora Rocha, Trad., pp. 231-69). Rio de Janeiro: Fundação Getúlio Vargas.

Souza, R. F. de. (2000). Inovação educacional no século XIX: a construção do currículo da escola primária no Brasil. Cad. CEDES, 20(51), pp. 9-28. 
Teixeira, G. B. (2008). O grande mestre da escola: os livros de leitura para a escola primária da capital do Império brasileiro. (Dissertação de Mestrado em Educação), Universidade Estadual do Rio de Janeiro, Rio de Janeiro, Brasil. Rio de Janeiro.

\section{Notas}

\footnotetext{
${ }^{1}$ A versão deste trabalho foi apresentada no IX Congresso Brasileiro de História da Educação de 2017.

${ }^{2}$ Ver Munakata, (2012).

${ }^{3}$ Ver Silva (2012).

${ }^{4}$ A autora menciona, também, que livros sobre a disciplina história foram utilizados como livros de leitura.

${ }^{5}$ Idem.

${ }^{6}$ O padre e seus livros são objetos de minha tese de doutoramento, em andamento.

${ }^{7} \mathrm{O}$ religioso foi preso em abril de 1874, por sua posição dentro da Igreja Católica, considerado um bispo reformador e por ser um dos bispos, juntamente, com D. Vital, que estiveram a frente do episódio conhecido como "Questão Religiosa".

${ }^{8}$ Por exemplo, tomo a viagem para campinas (SP) quando visitou o centro de ciências, letras e artes, em 1909 com objetivo de perceber e ser percebido nacionalmente.

${ }_{9}^{9}$ Compêndio de História do Brasil, em cinco volumes e Lições de História do Brasil.

${ }^{10}$ Conservo grafia original do livro.

${ }^{11}$ Conservo grafia original do livro.

${ }^{12}$ Nossa pátria. Pequena História do Brasil Para uso das escolas primárias, de Mário Vasconcelos da Veiga Cabral (1923); Noções de Corografia do Brasil, para uso das classes primárias, de Joaquim Osório Duque-Estrada (1921); Lições de História do Brasil para uso das classes primárias, Joaquim Manuel de Macedo (1877); Lições de História do Brasil para uso das classes primárias, de Luís Queiroz de Matoso Maia (1905); Conheçamos Nossa pátria, Joaquim José de Meneses Vieira (1892); Através do Brasil, de Manuel Bonfim e Olavo Bilac (1910); Minha terra eminha gente, de Afrânio Peixoto (1915); Rudimentos de História do Brasil, autoria de João Ribeiro (1924); A história do Brasil ensinada pela biografia de seus heróis, de Sylvio Romero (1890); Homens e fatos da história pátria, estudos biográficos segundo a ordem estabelecida no programa das escolas primárias, de José Maria Velho da Silva (1895); Pequena história do Brasil, Francisco F Mendes Vianna e Euclides Mendes (1922); 24 pontos de História do Brasil segundo o programa oficial, por Amélia de Resende Martins (1923);Resumo da História do Brasil para uso das escolas primárias, por Maria Guilhermina Loureiro de Andrade (1894).

${ }^{13}$ Conservo a grafia original do livro.
} 